\title{
Simulation of distant tsunami propagation with a radial loading deformation effect
}

\author{
Daisuke Inazu and Tatsuhiko Saito \\ National Institute for Earth Science and Disaster Prevention, 3-1 Tennodai, Tsukuba, Ibaraki 305-0006, Japan
}

(Received October 29, 2012; Revised March 18, 2013; Accepted March 19, 2013; Online published September 17, 2013)

\begin{abstract}
A simple parameterization of the loading deformation of the seafloor is incorporated into a tsunami simulation model in order to realistically calculate tsunami travel time, especially at regions far from the source. The parameterization uses one scalar parameter that is optimized effectively by far-field, deep-sea records of recent giant tsunamis: the 2011 Tohoku and the 2010 Chilean tsunamis. Using this parameterization with the optimal values, the observed tsunamis are realistically simulated in both near and far fields. The optimal values seem equivalent for both giant tsunamis, and are relatively smaller than those previously verified for ocean tide modeling, which is reasonable because of the shorter wavelengths of tsunamis.
\end{abstract}

Key words: Tsunami, travel time, self-attraction and loading.

\section{Introduction}

Tsunami propagation has been simulated by long-wave (non-dispersive) equations, and this approximation has been applied to model observed tsunamis especially in near fields (e.g., Aida, 1969; Satake, 1985; Tsushima et al., 2011). Recently, trans-oceanic tsunami simulations, with travel distances exceeding thousands of kilometers, have reported apparent travel time differences between simulations and observations. The simulated travel times of the leading tsunamis at regions further than $10000 \mathrm{~km}$ from their sources were systematically shorter than those of observations by 15-20 minutes for cases of recent giant tsunamis generated by the 2004 Sumatra (Rabinovich et al., 2011), the 2010 Chilean (Kato et al., 2011; Fujii and Satake, 2013), and the 2011 Tohoku (Tang et al., 2012; Grilli et al., 2013) earthquakes. The leading wave of the simulated tsunamis by these ordinary tsunami models propagates with a phase velocity of $\sqrt{g H}$ where $g$ is the gravity acceleration and $H$ is the water depth. We need to provide an appropriate mechanism of the delayed propagation found in the observations and its advanced modeling.

Wave dispersion can make the phase velocity slower than the non-dispersive $\sqrt{g H}$. Two types of wave dispersion are suggested: in short wavelengths $\left(<10^{2} \mathrm{~km}\right)$ and in long wavelengths $\left(>10^{3} \mathrm{~km}\right)$.

The phase velocity due to the short-wavelength dispersion is well known as $\sqrt{\frac{g \tanh (k H)}{k}}$ where $k$ is the wavenumber. This wave dispersion arises as wave trains subsequent to the leading wave (e.g., Lamb, 1932; Takahashi, 1942; Kajiura, 1963; Saito et al., 2010).

Meanwhile, interactions between an elastic Earth and

Copyright (c) The Society of Geomagnetism and Earth, Planetary and Space Sciences (SGEPSS); The Seismological Society of Japan; The Volcanological Society of Japan; The Geodetic Society of Japan; The Japanese Society for Planetary Sciences; TERRAPUB.

doi: $10.5047 /$ eps.2013.03.010 a tsunami with long wavelengths have been theoretically predicted (Ward, 1980; Comer, 1984). The interactions can be recognized as another wave dispersion that arises from the elastic seafloor deformation due to the tsunami loading. The loading deformation produces a feedback on tsunami spatial patterns, and delays propagations of the leading tsunami with the longest wavelengths, as mentioned in the next section. Such a feedback is often called the ocean self-attraction and loading (SAL) effect (e.g., Ray, 1998).

It has been known that the SAL effect must be considered for precise ocean tide modeling, especially for global modeling (e.g., Ray, 1998). Precise calculations of the SAL effect need convolutions of the global distribution of oceanic mass loading using spherical harmonics, Love numbers, and an Earth model (e.g., Farrell, 1972; Kantha and Clayson, 2000; Matsumoto et al., 2000), requiring relatively higher computational costs than ordinary tsunami models. On the other hand, the SAL effect can be modeled by a simple parameterization using one scalar parameter (e.g., Accad and Pekeris, 1978; Parke, 1982) without a substantial increase in computational costs. This parameterization yields less accurate results than the convolution method, but is better than modeling without any loading effects. The SAL effects have been also implemented in modern ocean general circulation modeling beyond the ocean tide (e.g., Stepanov and Hughes, 2004; Tamisiea et al., 2010).

The SAL effects have so far not been taken into account in tsunami propagation modeling. In the present study, a SAL effect is considered in a tsunami propagation model in order to examine the discrepancy of the simulated travel time. We implement a simple parameterization based on Accad and Pekeris (1978), and demonstrate that the parameterization works to simulate realistic travel times and waveforms of near- and far-field tsunamis. The efficiency of 
the parameterization is examined by considering case studies of two giant tsunamis generated by the 2011 Tohoku and the 2010 Chilean earthquakes. Discussions on the parameterized SAL effect are also made.

\section{Tsunami Simulation with SAL Effect}

Tsunami propagations are basically calculated by a longwave equation (e.g., Satake, 1985). Using a finite difference method, a linear long-wave model is numerically solved to calculate tsunami propagations over the global ocean in a transformed spherical coordinate (Inazu et al., 2012; Saito et al., 2013):

$$
\begin{aligned}
& \frac{\partial \mathbf{Q}}{\partial t}=-g H \nabla\left(\eta-\eta_{0}\right), \\
& \frac{\partial \eta}{\partial t}+\nabla \cdot \mathbf{Q}=0, \\
& \eta_{0}=\beta \eta,
\end{aligned}
$$

where $\mathbf{Q}$ and $\eta$ are the depth-integrated horizontal velocity and the tsunami height, respectively. $g$ is the acceleration due to gravity $\left(9.81 \mathrm{~m} / \mathrm{s}^{2}\right)$, and $H$ is the sea depth which is given based on the ETOPO1 bathymetric dataset (Amante and Eakins, 2009). The SAL effect, $\eta_{0}$, is added in the linear long-wave equation.

We apply a simple parameterization method using a constant scalar parameter $(\beta)$ that has been used for classical ocean tide modeling (Accad and Pekeris, 1978; Ray, 1998). The representation indicates that radial (vertical) seafloor deformation is caused by only the loading above (Fig. 1). The phase velocity derived from Eqs. (1)-(3) is:

$$
\sqrt{g H} \sqrt{1-\beta} .
$$

This shows that the tsunami propagation speed of the parameterization is slower than $\sqrt{g H}$, and is non-dispersive. An empirical value of $\beta=\sim 0.1$ has been sometimes used for ocean tide modeling (Ray, 1998; Kantha and Clayson, 2000). In the present study, the optimal $\beta$ for tsunamis is empirically determined by tsunami records obtained by deep-sea ocean bottom pressure (OBP) gauges.

Tsunami simulations start from initial conditions given by the source models: A model with a moment magnitude

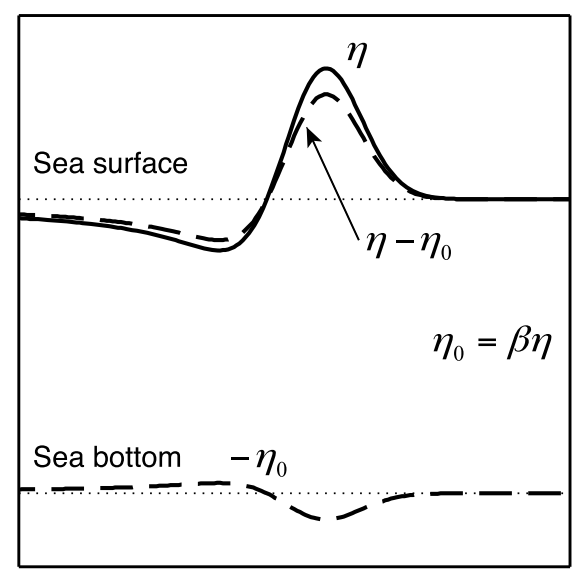

Fig. 1. Schematic of the SAL effect. $\eta$ (solid) is the tsunami height without the SAL effect, and $\eta_{0}$ (dashed) is the SAL term. $\eta-\eta_{0}$ (dashed) is the modified tsunami height. of 9.0 based on the inversion analysis by Saito et al. (2011) is used for the 2011 Tohoku tsunami. A rectangular fault model with a moment magnitude of 8.8 , the same as that of Kimura et al. (2013), is used for the 2010 Chilean tsunami.

\section{Basin-Wide Tsunami Data}

The giant tsunamis generated by the 2011 Tohoku and the 2010 Chilean earthquakes were recorded by basinwide OBP gauges operated by the Deep-Ocean Assessment and Reporting of Tsunamis (DART) system (González et al., 1998), and by the seafloor cable system of the Japan Agency for Marine-Earth Science and Technology (JAMSTEC) (Momma et al., 1997; Hirata et al., 2002). The data shown in Fig. 2 are used for the respective tsunamis. KPG1 and MPG1 are operated by JAMSTEC, and other sites are DART stations.

\section{Validation of SAL Effect}

Improving the horizontal resolution $(10,5,2$, and 1 arcmin) in the tsunami simulation is first confirmed to yield no substantial changes in the calculated travel times of the leading tsunami even in far fields (Fig. 3). The SAL effect is investigated using the finest resolution and bathymetry of 1 arcmin.

We examine different loading factors: $\beta$ is tested within $0.000-0.040$ for every 0.005 . The simulated results are evaluated by the detided OBP data (Fig. 2). The accuracy of the simulations is measured by the root-mean-square (RMS) reduction of the observed tsunami for each OBP record. In the present study, the RMS reduction is evaluated at two-hour intervals containing the time when the leading tsunami reaches each OBP site, since the travel time is of focus. The RMS reduction is defined by a ratio of the residual RMS to the observed RMS:

$$
\frac{\mathrm{RMS}_{\text {observed-simulated }}}{\mathrm{RMS}_{\text {observed }}} \text {. }
$$

Significant RMS reduction is basically identified with maximum correlation coefficients with a zero lag between the observation and simulation. The loading factor $(\beta)$ is then optimized by the maximum RMS reduction.

In the case of simulation with the loading factor of $\beta=$ 0 (usual tsunami simulation), calculated travel times are shorter than observations, and the differences increase with distances from the source regions (Figs. 4 and 5(a)), as indicated by previous studies. Changing $\beta$ allows the calculation of realistic travel times, especially in far fields, and hardly affects near-field travel times (Fig. 4).

It is worth noting that the SAL effect should be included in order to simulate realistic tsunami propagation with travel times of longer than several hours, since the effective RMS reduction $(<1)$ could be impossible without the SAL effect (Fig. 5(c)). The calculated tsunami waveforms are hardly modified by changing $\beta$ (Fig. 4). $\beta$ is optimized more significantly by far-field tsunami data because travel times calculated without the SAL effect largely deviates in the far fields (Fig. 5). Simulations with $\beta=0.015-$ 0.020 can correct the deviated travel times close to realistic values, and yield an effective RMS reduction at most OBP sites (Fig. 5 and Table 1). 

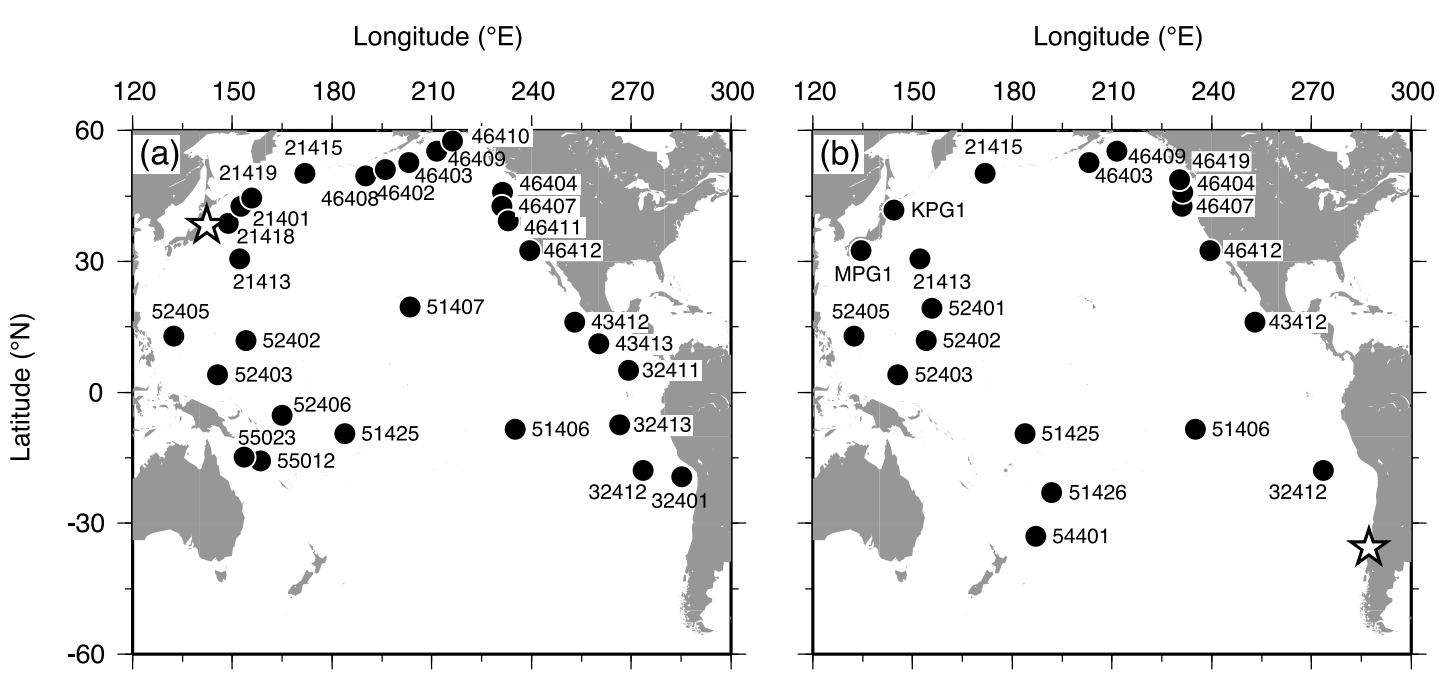

Fig. 2. Locations of OBP data used for (a) the 2011 Tohoku (28 sites), and (b) the 2010 Chilean (20 sites) tsunamis. Stars denote the respective sources.

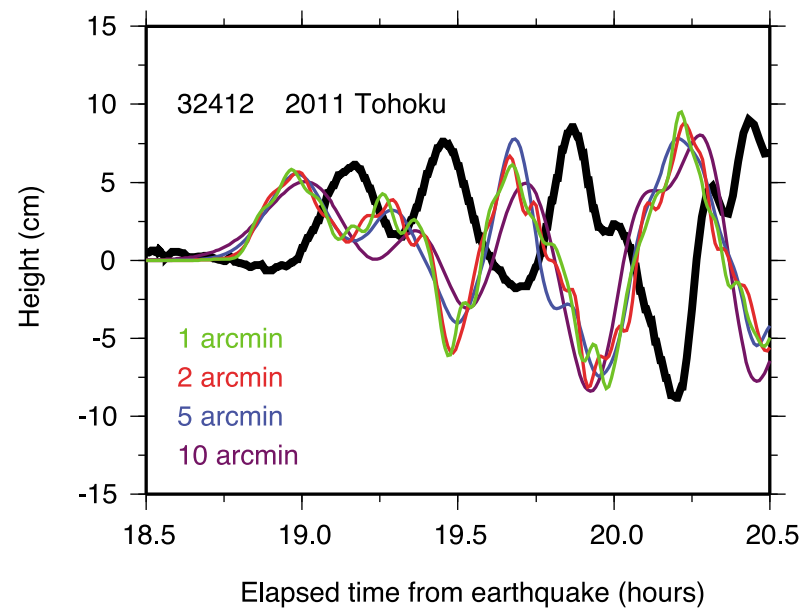

Fig. 3. Observed tsunami (black) and simulated results (colored) without the loading effect $(\beta=0)$ for different horizontal resolutions of the simulation (10, 5, 2, and 1 arcmin).

\section{Discussions on the Optimal $\beta$}

\section{$5.1 \beta$ and spatial scale of loading deformation}

For ocean tide modeling, the optimal $\beta$ was $\sim 0.12$ for diurnal constituents and $\sim 0.08$ for semidiurnal constituents (Parke, 1982; Ray, 1998). In general, the loading deformation is significant for spatially large loading. Wavelengths of tsunamis are, at most, hundreds of kilometers and are shorter than those of ocean tides that are thousands of kilometers. Thus, deformation efficiency against tsunami loading is expected to be relatively weaker than that for ocean tide loading. The deformation efficiency is simply evaluated by a deformation equation of an elastic halfspace based on Jeffreys (1976),

$$
d=\frac{(1-v)}{\mu k} \rho g \eta_{1} \cos k x,
$$

where $d$ is the vertical crustal deformation, $\mu$ is the rigidity ( $30-40 \mathrm{GPa}), v$ is Poisson's ratio $(\sim 0.3), \rho$ is the seawater density $\left(1030 \mathrm{~kg} / \mathrm{m}^{3}\right), k$ is the wavenumber, and $\rho g \eta_{1} \cos k x$ is the applied pressure loading with a spatial distribution in the horizontal $(x)$ direction. Since we put $\rho g \eta_{1} \cos k x=\rho g \eta$ and then $d \approx \beta \eta$ as the SAL effect in the present study, calculated wavelengths for the giant tsunamis $(\beta=0.015-0.020)$ are $400-700 \mathrm{~km}$. The spatial scales seem reasonable and equivalent for the two tsunamis. It is also noted that, for example, a 1-m tsunami loading bearing such spatial scales generates an elastic, vertical seafloor deformation of $1.5-2.0 \mathrm{~cm}$.

The difference between the phase velocities with, and without, the SAL effect is $\sqrt{g H}(1-\sqrt{1-\beta}) \approx \sqrt{g H} \frac{\beta}{2}$, being $0.8-1.0 \%$ with the optimal $\beta$. Meanwhile, the simulation without the SAL effect shows an apparent linear discrepancy for the travel time commonly for both tsunamis (Fig. 5(a)). The linear discrepancy agrees with the difference of the phase velocities. The optimal $\beta$ common for both the tsunamis is also verified from Fig. 5(a), because the phase velocity represented by Eq. (4) indicates a linear deviation from $\sqrt{g H}$.

\subsection{Effect of ocean density stratification on $\beta$}

It has been mentioned above that the distant tsunami propagation is basically explained by the long-wave approximation, i.e., a one-layer ocean model, and the elastic loading deformation. In a strict sense, it is known that the density structure of the real ocean contributes to the slow propagation of ocean gravity waves. So the optimal $\beta$ to some extent includes the effects of the density structure of the ocean as well. This effect is evaluated in this subsection.

An ocean model that considers ocean stratification is necessary, in general, so as to represent realistic ocean circulations. Two-layer ocean models that are simplest, essential ones have been often used. The long-wave phase velocity in a stratified ocean is revisited using a two-layer ocean model. A well known dispersion relation in the two-layer ocean model has been derived by Gill (1982) and Unoki (1993):

$$
\begin{aligned}
& \left(\frac{\omega}{k}\right)^{4}-g\left(h_{1}+h_{2}\right)\left(\frac{\omega}{k}\right)^{2}+\varepsilon g^{2} h_{1} h_{2}=0, \\
& \varepsilon=\frac{\rho_{2}-\rho_{1}}{\rho_{2}}
\end{aligned}
$$

where $\omega$ is the angular frequency. Subscripts 1 and 2 denote 

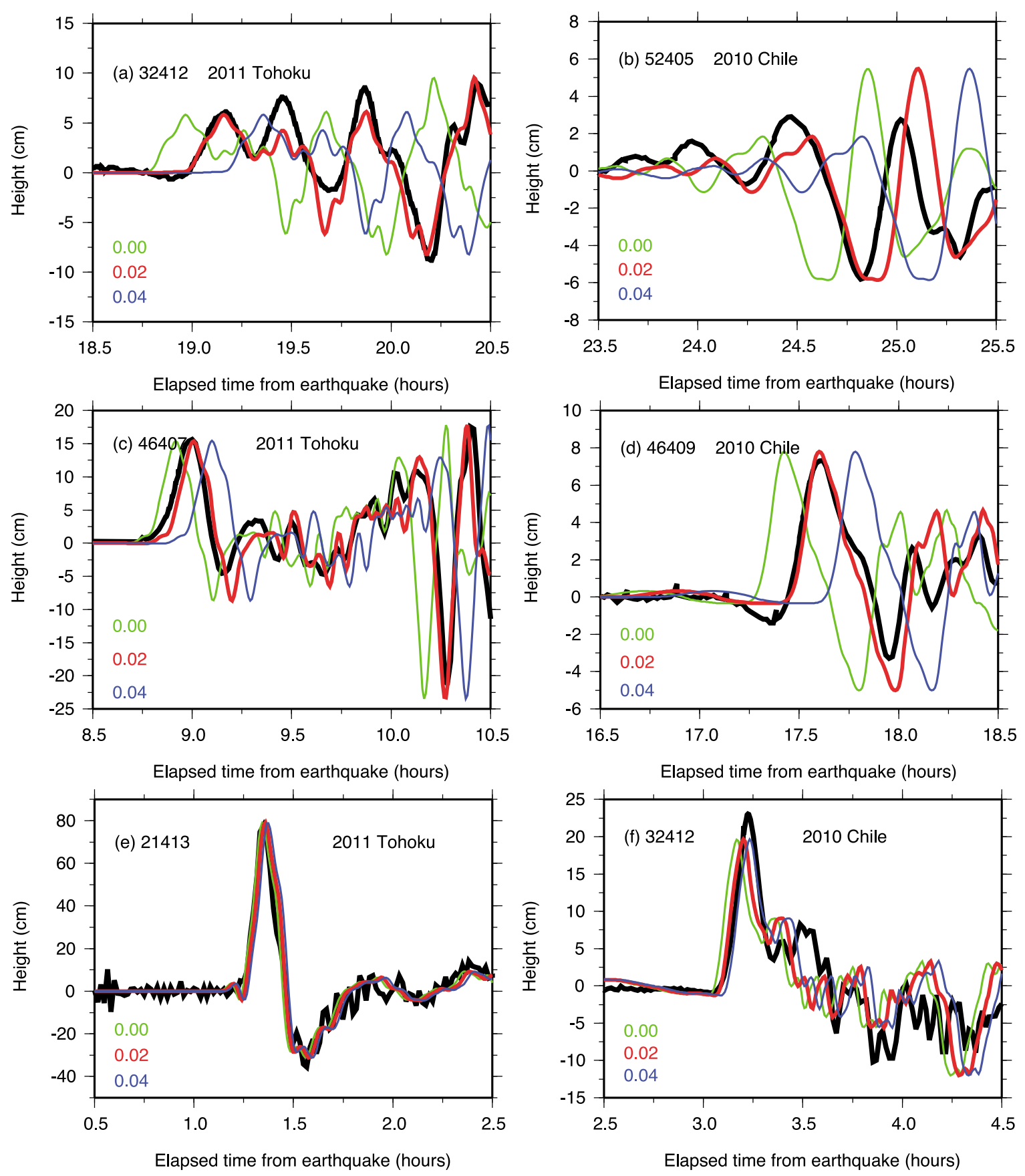

Fig. 4. Comparisons of observed tsunamis (black) with simulated results (colored) using different $\beta(0.000,0.020$, and 0.040) at selected OBP sites. Left and right panels show the 2011 Tohoku and the 2010 Chilean tsunamis, respectively. These are typical examples in far (a, b), intermediate (c, d), and near $(e, f)$ fields from the respective tsunami sources.

upper and lower layers in the two-layer ocean. $h$ and $\rho$ are the layer thickness and density of each layer, respectively. $h_{1}+h_{2}$ is the total depth. This equation yields two roots as phase velocities of the surface gravity wave $\left(C_{+}\right)$and the internal gravity wave $\left(C_{-}\right)$:

$$
\begin{aligned}
\left(\frac{\omega}{k}\right)^{2}= & \frac{1}{2} g\left(h_{1}+h_{2}\right)\left[1 \pm \sqrt{1-4 \varepsilon \frac{h_{1} h_{2}}{\left(h_{1}+h_{2}\right)^{2}}}\right] \\
\approx & \frac{1}{2} g\left(h_{1}+h_{2}\right) \\
& \times\left[1 \pm\left\{1-2 \varepsilon \frac{h_{1} h_{2}}{\left(h_{1}+h_{2}\right)^{2}}+O\left(\varepsilon^{2}\right)\right\}\right]
\end{aligned}
$$

$$
\begin{aligned}
& C_{+}=\frac{\omega_{+}}{k} \approx \sqrt{g\left(h_{1}+h_{2}\right)} \sqrt{1-\varepsilon \frac{h_{1} h_{2}}{\left(h_{1}+h_{2}\right)^{2}}} \\
& C_{-}=\frac{\omega_{-}}{k} \approx \sqrt{\varepsilon g \frac{h_{1} h_{2}}{h_{1}+h_{2}}}
\end{aligned}
$$

$C_{+}$is mostly $\sqrt{g\left(h_{1}+h_{2}\right)}$ because $\varepsilon$ is small, as little as $10^{-3}$ in deep seas (e.g., Kindle and Thompson, 1989; Qiu, 2003; Pierini, 2006) and $10^{-2}$ in coastal seas (Gill, 1982; Unoki, 1993).

Here, a deviation factor $\sqrt{1-\varepsilon \frac{h_{1} h_{2}}{\left(h_{1}+h_{2}\right)^{2}}}$ is re-evaluated. For example, a two-layer model for investigating the 
Table 1. Summary of the simulated results for (a) the 2011 Tohoku, and (b) the 2010 Chilean tsunamis at each OBP site. The results for $\beta^{*}$ (=0.015) are also shown.

\begin{tabular}{|c|c|c|c|c|c|c|c|c|c|c|}
\hline Site & $\begin{array}{l}\text { Latitude } \\
\left({ }^{\circ} \mathrm{N}\right)\end{array}$ & $\begin{array}{c}\text { Longitude } \\
\left({ }^{\circ} \mathrm{E}\right)\end{array}$ & $\begin{array}{l}\text { Depth } \\
(\mathrm{m})\end{array}$ & $\begin{array}{c}\text { Epicentral } \\
\text { distance } \\
(\mathrm{km})\end{array}$ & $\begin{array}{c}\text { Travel } \\
\text { time } \\
(\mathrm{hr})\end{array}$ & $\begin{array}{c}\text { Lag for } \\
\beta=0 \\
(\min )\end{array}$ & $\begin{array}{c}\text { RMS } \\
\text { reduction } \\
\text { for } \beta=0\end{array}$ & $\begin{array}{c}\text { Optimal } \\
\beta\end{array}$ & $\begin{array}{c}\text { Lag for } \\
\beta^{*} \\
(\mathrm{~min}) \\
\end{array}$ & $\begin{array}{c}\text { RMS } \\
\text { reduction } \\
\text { for } \beta^{*}\end{array}$ \\
\hline 21418 & 38.711 & 148.694 & 5663 & 552 & 0.5 & -0.5 & 0.52 & 0.000 & -0.5 & 0.55 \\
\hline 21401 & 42.617 & 152.583 & 5264 & 987 & 1.1 & 0.0 & 0.35 & 0.000 & -0.5 & 0.39 \\
\hline 21413 & 30.515 & 152.117 & 5825 & 1246 & 1.3 & 0.0 & 0.26 & 0.000 & -1.0 & 0.32 \\
\hline 21419 & 44.455 & 155.736 & 5292 & 1306 & 1.5 & -0.5 & 0.33 & 0.000 & -1.5 & 0.40 \\
\hline 21415 & 50.183 & 171.847 & 4710 & 2670 & 3.2 & 0.0 & 0.35 & 0.000 & -1.5 & 0.48 \\
\hline 46408 & 49.626 & 190.129 & 5379 & 3952 & 4.7 & 1.5 & 0.57 & 0.010 & -1.0 & 0.53 \\
\hline 46402 & 51.068 & 195.980 & 4719 & 4364 & 5.3 & 3.0 & 0.88 & 0.015 & 0.5 & 0.65 \\
\hline 46403 & 52.650 & 203.057 & 4514 & 4837 & 5.9 & 6.0 & 0.95 & 0.030 & 3.0 & 0.89 \\
\hline 46409 & 55.300 & 211.485 & 4189 & 5344 & 6.8 & 6.5 & 0.92 & 0.000 & 3.0 & 0.79 \\
\hline 46410 & 57.635 & 216.214 & 3729 & 5584 & 7.3 & 3.5 & 0.66 & 0.015 & 0.0 & 0.43 \\
\hline 52402 & 11.883 & 154.116 & 5862 & 3165 & 3.8 & 1.5 & 0.39 & 0.015 & 0.0 & 0.27 \\
\hline 52403 & 4.052 & 145.592 & 4432 & 3828 & 5.2 & 1.0 & 0.40 & 0.010 & -1.0 & 0.39 \\
\hline 52405 & 12.881 & 132.333 & 5923 & 3001 & 4.1 & 2.0 & 0.30 & 0.015 & 0.0 & 0.23 \\
\hline 52406 & -5.293 & 165.002 & 1798 & 5388 & 6.8 & 3.0 & 0.59 & 0.015 & 0.0 & 0.31 \\
\hline 51425 & -9.510 & 183.759 & 4978 & 6839 & 8.2 & 1.0 & 0.53 & 0.005 & -3.0 & 0.63 \\
\hline 55012 & -15.799 & 158.400 & 3284 & 6252 & 8.9 & 4.5 & 0.71 & 0.015 & 0.0 & 0.44 \\
\hline 55023 & -14.800 & 153.580 & 4595 & 6028 & 9.6 & 4.0 & 0.83 & 0.015 & -0.5 & 0.66 \\
\hline 51407 & 19.591 & 203.415 & 4683 & 6183 & 7.8 & 6.0 & 0.88 & 0.025 & 2.0 & 0.64 \\
\hline 51406 & -8.480 & 234.973 & 4450 & 10828 & 13.6 & 9.5 & 1.38 & 0.025 & 3.5 & 0.87 \\
\hline 46404 & 45.858 & 231.232 & 2738 & 6999 & 8.9 & 5.5 & 1.07 & 0.020 & 1.0 & 0.58 \\
\hline 46407 & 42.605 & 231.103 & 3266 & 7165 & 9.0 & 6.0 & 1.36 & 0.020 & 1.5 & 0.59 \\
\hline 46411 & 39.349 & 232.979 & 4260 & 7486 & 9.3 & 5.0 & 1.08 & 0.015 & 0.5 & 0.38 \\
\hline 46412 & 32.456 & 239.442 & 3718 & 8398 & 10.4 & 4.0 & 1.05 & 0.015 & -0.5 & 0.68 \\
\hline 43412 & 16.069 & 253.004 & 3233 & 10619 & 13.6 & 8.5 & 1.48 & 0.020 & 2.5 & 0.74 \\
\hline 43413 & 11.065 & 260.147 & 3404 & 11563 & 15.0 & 8.5 & 1.67 & 0.020 & 1.5 & 0.63 \\
\hline 32411 & 4.999 & 269.159 & 3167 & 12741 & 16.8 & 11.0 & 1.63 & 0.020 & 3.0 & 1.01 \\
\hline 32413 & -7.397 & 266.500 & 3894 & 13479 & 17.4 & 10.5 & 1.45 & 0.020 & 2.5 & 0.99 \\
\hline 32412 & -17.975 & 273.608 & 4326 & 14816 & 19.2 & 12.0 & 1.64 & 0.020 & 3.0 & 0.67 \\
\hline \multicolumn{11}{|c|}{ (b) 2010 Chilean tsunami } \\
\hline Site & $\begin{array}{l}\text { Latitude } \\
\left({ }^{\circ} \mathrm{N}\right)\end{array}$ & $\begin{array}{l}\text { Longitude } \\
\quad\left({ }^{\circ} \mathrm{E}\right)\end{array}$ & $\begin{array}{l}\text { Depth } \\
(\mathrm{m})\end{array}$ & $\begin{array}{c}\text { Epicentral } \\
\text { distance } \\
(\mathrm{km})\end{array}$ & $\begin{array}{c}\text { Travel } \\
\text { time } \\
(\mathrm{hr})\end{array}$ & $\begin{array}{c}\text { Lag for } \\
\beta=0 \\
(\min )\end{array}$ & $\begin{array}{c}\text { RMS } \\
\text { reduction } \\
\text { for } \beta=0\end{array}$ & $\begin{array}{c}\text { Optimal } \\
\beta\end{array}$ & $\begin{array}{c}\text { Lag for } \\
\beta^{*} \\
(\min )\end{array}$ & $\begin{array}{c}\text { RMS } \\
\text { reduction } \\
\text { for } \beta^{*}\end{array}$ \\
\hline 32412 & -17.975 & 273.608 & 4326 & 2375 & 3.2 & 3.5 & 0.69 & 0.030 & 1.5 & 0.59 \\
\hline 43412 & 16.069 & 253.004 & 3233 & 6787 & 9.8 & 6.5 & 0.96 & 0.020 & 2.0 & 0.81 \\
\hline 51406 & -8.480 & 234.973 & 4481 & 6089 & 8.9 & 2.5 & 0.77 & 0.010 & -1.5 & 0.68 \\
\hline 46412 & 32.456 & 239.442 & 3718 & 9065 & 13.1 & 6.5 & 1.18 & 0.015 & 0.5 & 0.59 \\
\hline 46407 & 42.605 & 231.103 & 3266 & 10402 & 14.9 & 7.0 & 1.26 & 0.015 & 0.0 & 0.68 \\
\hline 46404 & 45.858 & 231.232 & 2739 & 10662 & 15.6 & 7.0 & 1.21 & 0.015 & -0.5 & 0.81 \\
\hline 46419 & 48.766 & 230.367 & 2777 & 10942 & 16.1 & 8.0 & 1.08 & 0.015 & 0.5 & 0.68 \\
\hline 54401 & -33.005 & 187.015 & 5836 & 8766 & 11.6 & 2.0 & 0.88 & 0.005 & -3.5 & 0.97 \\
\hline 51426 & -22.993 & 191.867 & 5681 & 9016 & 11.9 & 1.0 & 0.95 & 0.000 & -5.0 & 1.01 \\
\hline 51425 & -9.510 & 183.759 & 4963 & 10603 & 14.4 & 4.0 & 0.94 & 0.010 & -2.0 & 0.88 \\
\hline 46409 & 55.300 & 211.485 & 4191 & 12396 & 17.6 & 9.0 & 1.50 & 0.015 & 1.0 & 0.59 \\
\hline 46403 & 52.650 & 203.057 & 4512 & 12730 & 17.6 & 10.5 & 1.44 & 0.020 & 2.5 & 0.82 \\
\hline 21415 & 50.183 & 171.847 & 4710 & 14703 & 19.5 & 12.0 & 1.15 & 0.020 & 3.0 & 0.89 \\
\hline 21413 & 30.515 & 152.117 & 5827 & 15851 & 21.6 & 11.5 & 1.34 & 0.020 & 1.5 & 0.69 \\
\hline 52401 & 19.261 & 155.771 & 5571 & 14971 & 21.1 & 8.5 & 1.49 & 0.015 & -1.0 & 0.63 \\
\hline 52402 & 11.883 & 154.116 & 5862 & 14653 & 20.7 & 9.0 & 1.29 & 0.015 & -0.5 & 0.46 \\
\hline 52403 & 4.0520 & 145.592 & 4432 & 14769 & 22.1 & 9.5 & 1.52 & 0.015 & -0.5 & 0.68 \\
\hline 52405 & 12.881 & 132.333 & 5923 & 16476 & 24.0 & 10.0 & 1.62 & 0.015 & -1.5 & 0.57 \\
\hline KPG1 & 41.704 & 144.438 & 2218 & 16760 & 22.0 & 11.0 & 1.20 & 0.015 & 0.5 & 0.69 \\
\hline MPG1 & 32.391 & 134.475 & 2308 & 17510 & 23.8 & 14.0 & 1.15 & 0.020 & 3.0 & 0.67 \\
\hline
\end{tabular}




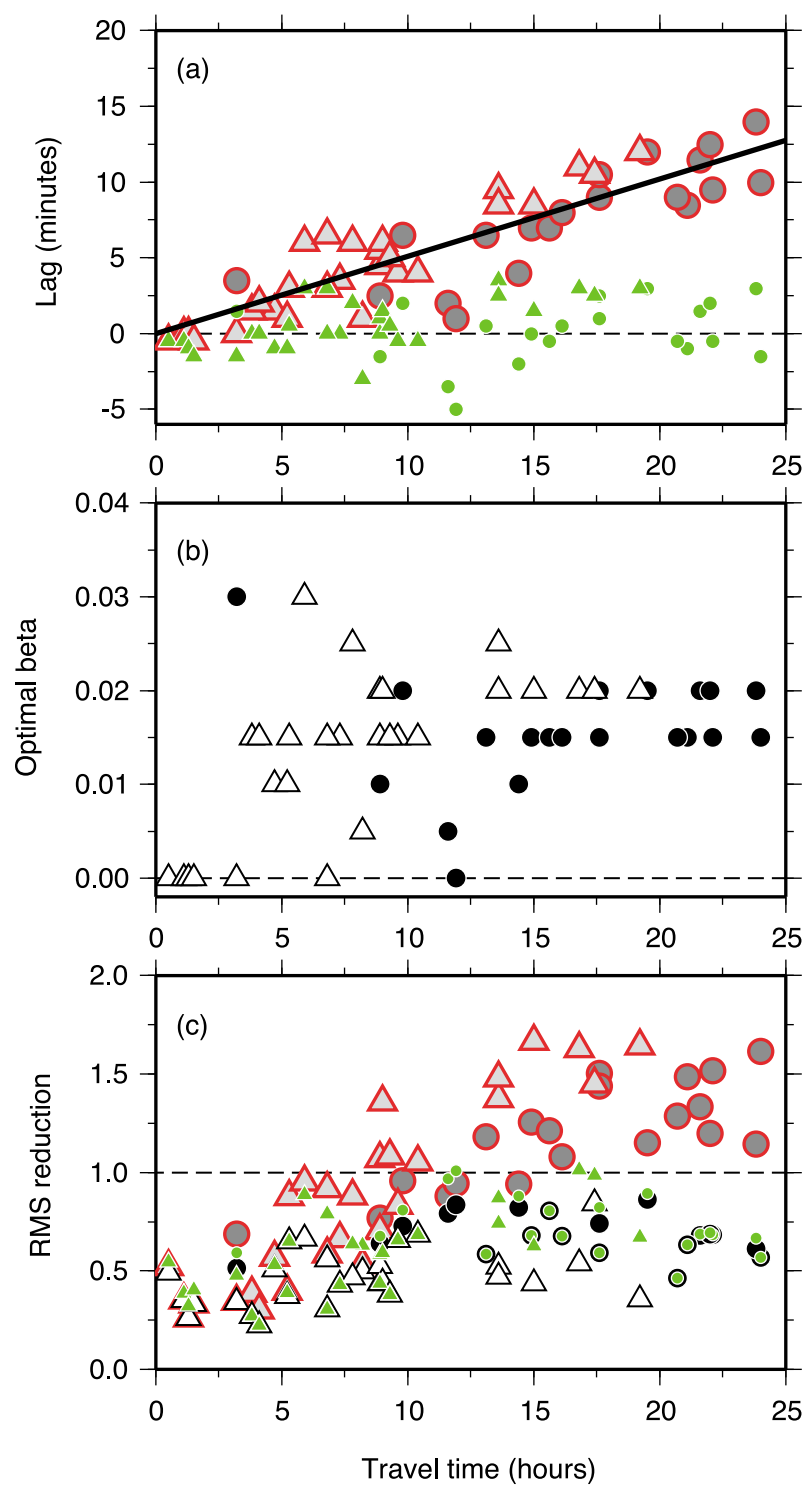

Fig. 5. (a) Lags with maximum correlation coefficients between the observation and the simulation with (green)/without (red) the SAL effect, (b) optimal SAL factor $(\beta)$ based on the maximum RMS reduction of the observation, and (c) RMS reduction of the observation by simulated results. These are shown as a function of the observed travel times at each OBP site. The linear fit in (a) shows a slope of $0.85 \%$. Red and black indicate results without the SAL effect $(\beta=0)$ and those with the optimal $\beta$ at each OBP site, respectively. The results using $\beta=0.015$ is shown by green plots in (a) and (c). Triangles and circles indicate results for the 2011 Tohoku and the 2010 Chilean tsunamis, respectively. The values for the plots are listed in Table 1 .

Kuroshio current, by Isobe and Imawaki (2002) used parameters of $h_{1}=600 \mathrm{~m}, h_{2}=2400 \mathrm{~m}$, and $\varepsilon=0.0020$, and give a deviation factor of 0.99984. Parameters found in other several two-layer models on western boundary currents (Hurlburt, 1986; Yoon and Yasuda, 1987; Endoh and Hibiya, 2000) give a deviation factor 0.99981-0.99990, being a $0.01-0.02 \%$ deviation from $\sqrt{g\left(h_{1}+h_{2}\right)}$. Therefore, the delay of the distant tsunami propagation behind $\sqrt{g H}$ (0.8-1.0\% deviation) arises mostly from the SAL effect, and weakly from ocean density stratification. Similar considerations have recently been conducted also by Watada et al. (2012) and Tsai et al. (2013).

\section{Summary and Perspective}

A simple parameterization of radial seafloor deformation due to tsunami loading is implemented in a global tsunami propagation model. This loading effect can well account for observed leading tsunamis especially in terms of the far-field travel time from their source regions. Optimal values of the scalar parameter are $\beta=0.015-0.020$, and equivalent for both cases of the 2011 Tohoku and the 2010 Chilean tsunamis. The optimal $\beta$ indicates that the spatial scales of giant tsunamis are $400-700 \mathrm{~km}$. A tsunami with such spatial scales generates an elastic, vertical seafloor deformation: for example, a $1.5-2.0 \mathrm{~cm}$ subsidence of the seafloor is generated in response to a 1-m tsunami loading. As a consequence, the phase velocity of a giant tsunami is slower than $\sqrt{g H}$ by $\sim 1 \%$.

We recommend that the loading effect is considered for simulating distant tsunami propagations with travel times in excess of several hours where discrepancies of simulation without loading effects result in tsunami arrivals of more than several minutes earlier than the observed tsunami (Fig. 5). Though a smaller $\beta$ may be preferred for tsunamis with smaller spatial scales, whose seismic magnitudes are probably smaller $(M<7-8)$, such smaller tsunamis become invisible in far fields. Also, changing $\beta$ barely deteriorates simulated results, including tsunami waveforms, for near-field calculations (Figs. 4(e)-(f)). Thus, from the viewpoint of practical purposes, tsunami calculations using parameterization with the optimal value will also be useful for moderate tsunamis, as well as giant ones. Owing to an easy implementation and no increase in computational costs compared to standard long-wave calculations, the proposed method will immediately work for the early prediction/warning of future great tsunamis in both near and far fields (e.g., Wei et al., 2008; Tang et al., 2009; Tsushima et al., 2011), and possibly enable source inversions with Green's functions including far-field data (e.g., Fujii and Satake, 2013).

The loading parameterization proposed in this study is the same method as used for classical ocean tide modeling. As already noted by ocean tide modelers, convolutions of the whole global oceanic mass loading, rather than a simplified parameterization, are preferred to more precisely calculate the loading deformation and its feedback (Ray, 1989; Matsumoto et al., 2000). Also, the interaction may be appropriately solved by a recent advanced simulation scheme of Maeda and Furumura (2013) to collectively calculate seismic waves, ocean acoustic waves, and tsunamis. More powerful computer facilities than current supercomputer systems will be required to enable these precise tsunami calculations.

Acknowledgments. The OBP data were downloaded from the websites of DART (http://www.ndbc.noaa.gov/dart.shtml) and JAMSTEC (http://www.jamstec.go.jp/scdc/top_e.html). Numerical simulations were carried out by the Altix 4700 supercomputer system of the National Institute for Earth Science and Disaster Prevention. We thank two reviewers for their valuable comments.

\section{References}

Accad, Y. and C. L. Pekeris, Solution of the tidal equations for the $\mathrm{M}_{2}$ and $\mathrm{S}_{2}$ tides in the world oceans from a knowledge of the 
tidal potential alone, Phil. Trans. R. Soc. Lond. A, 290, 235-266, doi:10.1098/rsta.1978.0083, 1978.

Aida, I., Numerical experiments for the tsunami propagation-the 1964 Niigata tsunami and the 1968 Tokachi-oki tsunami, Bull. Earthq. Res. Inst., 47, 673-700, 1969.

Amante, C. and B. W. Eakins, ETOPO1 1 arc-minute global relief model: Procedures, data sources and analysis, NOAA Tech. Memo. NESDIS NGDC-24, 19 pp., 2009.

Comer, R. P., The tsunami mode of a flat earth and its excitation by earthquake sources, Geophys. J. R. Astron. Soc., 77, 1-27, doi:10.1111/j.1365-246X.1984.tb01923.x, 1984.

Endoh, T. and T. Hibiya, Numerical study of the generation and propagation of trigger meanders of the Kuroshio south of Japan, J. Oceanogr., 56, 409-418, doi:10.1023/A:1011176322166, 2000.

Farrell, W. E., Deformation of the Earth by surface loads, Rev. Geophys Space Phys., 10, 761-797, doi:10.1029/RG010i003p00761, 1972.

Fujii, Y. and K. Satake, Slip distribution and seismic moment of the 2010 and 1960 Chilean earthquakes inferred from tsunami waveforms and coastal geodetic data, Pure Appl. Geophys., 170, 1493-1509, doi:10.1007/s00024-012-0524-2, 2013.

Gill, A. E., Adjustment under gravity of a density-stratified fluid, in Atmosphere-Ocean Dynamics, p. 117-188, Academic Press, San Diego, 1982.

González, F. I., H. M. Milburn, E. N. Bernard, and J. Newman, Deepocean assessment and reporting of tsunamis (DART): Brief overview and status report, Proc. Int. Works. Tsunami Disaster Mitigation, 118129, 1998.

Grilli, S. T., J. C. Harris, T. S. T. Bakhsh, T. L. Masterlark, C. Kyriakopolos, J. T. Kirby, and F. Shi, Numerical simulation of the 2011 Tohoku tsunami based on a new transient FEM co-seismic source: Comparison to far- and near-field observations, Pure Appl. Geophys., 170, 13331359, doi:10.1007/s00024-012-0528-y, 2013

Hirata, K., M. Aoyagi, H. Mikada, K. Kawaguchi, Y. Kaiho, R. Iwase, S. Morita, I. Fujisawa, H. Sugioka, K. Mitsuzawa, K. Suehiro, H. Kinoshita, and N. Fujiwara, Real-time geophysical measurements on the deep seafloor using submarine cable in the southern Kurile subduction zone, IEEE J. Oceanic Eng., 27, 170-181, doi:10.1109/JOE.2002.1002471, 2002.

Hurlburt, H. E., Dynamic transfer of simulated altimeter data into subsurface information by a numerical ocean model, J. Geophys. Res.Oceans, 91, 2372-2400, doi:10.1029/JC091iC02p02372, 1986.

Inazu, D., R. Hino, and H. Fujimoto, A global barotropic ocean model driven by synoptic atmospheric disturbances for detecting seafloor vertical displacements from in situ ocean bottom pressure measurements, Mar. Geophys. Res., 33, 127-148, doi:10.1007/s11001-012-9151-7, 2012.

Isobe, A. and S. Imawaki, Annual variation of the Kuroshio transport in a two-layer numerical model with a ridge, J. Phys. Oceanogr., 32, 9941009, doi:10.1175/1520-0485(2002)032<0994:AVOTKT>2.0.CO;2, 2002 .

Jeffreys, H., Stress-differences in the Earth, in The Earth: Its Origin, History and Physical Constitution, 6th ed., 263-285, Cambridge Univ. Press, New York, 1976.

Kajiura, K., The leading wave of a tsunami, Bull. Earthq. Res. Inst., 41, 535-571, 1963.

Kantha, L. H. and C. A. Clyason, Tides and tidal modeling, in Numerical Models of Oceans and Oceanic Processes, 375-492, Academic Press, San Diego, 2000.

Kato, T., Y. Terada, H. Nishimura, T. Nagai, and S. Koshimura, Tsunami records due to the 2010 Chile Earthquake observed by GPS buoys established along the Pacific coast of Japan, Earth Planets Space, 63, e5-e8, doi:10.5047/eps.2011.05.001, 2011.

Kimura, T., S. Tanaka, and T. Saito, Ground tilt changes in Japan caused by the 2010 Maule, Chile, earthquake tsunami, J. Geophys. Res.-Solid Earth, 118, 406-415, doi:10.1029/2012JB009657, 2013.

Kindle, J. C. and J. D. Thompson, The 26- and 50-day oscillations in the western Indian Ocean: Model results, J. Geophys. Res.-Oceans, 94, 4721-4736, doi:10.1029/JC094iC04p04721, 1989.

Lamb, H., Surface waves, in Hydrodynamics, 6th ed., p. 363-475, Dover, New York, 1932.

Maeda, T. and T. Furumura, FDM Simulation of seismic waves, ocean acoustic waves, and tsunamis based on tsunami-coupled equations of motion, Pure Appl. Geophys., 170, 109-127, doi:10.1007/s00024-0110430-z, 2013.

Matsumoto, K., T. Takanezawa, and M. Ooe, Ocean tide models devel- oped by assimilating TOPEX/POSEIDON altimeter data into hydrological model: A global model and a regional model around Japan, $J$. Oceanogr., 56, 567-581, doi:10.1023/A:1011157212596, 2000.

Momma, H., N. Fujisawa, K. Kawaguchi, R. Iwase, S. Suzuki, and H. Kinoshita, Monitoring system for submarine earthquakes and deep sea environment, Proc. Oceans 1997 Mar. Technol. Soc. IEEE Techno-Ocean 1997, 1453-1459, doi:10.1109/OCEANS.1997.624211, 1997.

Parke, M. E., O1, P1, N2 models of the global ocean tide on an elastic earth plus surface potential and spherical harmonic decompositions for M2, S2, and K1, Mar. Geod., 6, 35-81, doi:10.1080/15210608209379441, 1982.

Pierini, S., A Kuroshio Extension system model study: Decadal chaotic self-sustained oscillations, J. Phys. Oceanogr., 36, 1605-1625, doi:10.1175/JPO2931.1, 2006

Qiu, B., Kuroshio Extension variability and forcing of the Pacific decadal oscillations: Responses and potential feedback, J. Phys. Oceanogr., 33 2465-2482, doi:10.1175/2459.1, 2003.

Rabinovich, A. B., P. L. Woodworth, and V. V. Titov, Deep-sea observations and modeling of the 2004 Sumatra tsunami in Drake Passage, Geophys. Res. Lett., 38, L16604, doi:10.1029/2011GL048305, 2011.

Ray, R. D., Ocean self-attraction and loading in numerical tidal models, Mar. Geod., 21, 181-192, doi:10.1080/01490419809388134, 1998.

Saito, T., K. Satake, and T. Furumura, Tsunami waveform inversion including dispersive waves: The 2004 earthquake off Kii Peninsula, Japan, $J$. Geophys. Res.—Solid Earth, 115, B06303, doi:10.1029/2009JB006884, 2010.

Saito, T., Y. Ito, D. Inazu, and R. Hino, Tsunami source of the 2011 Tohoku-Oki earthquake, Japan: Inversion analysis based on dispersive tsunami simulations, Geophys. Res. Lett., 38, L00G19, doi:10.1029/2011GL049089, 2011

Saito, T., D. Inazu, S. Tanaka, and T. Miyoshi, Tsunami coda across the Pacific Ocean following the 2011 Tohoku-Oki earthquake, Bull. Seismol. Soc. Am., 103, 1429-1443, doi:10.1785/0120120183, 2013.

Satake, K., The mechanism of the 1983 Japan Sea earthquake as inferred from long-period surface waves and tsunamis, Phys. Earth Planet. Inter., 37, 249-260, doi:10.1016/0031-9201(85)90012-3, 1985.

Stepanov, V. N. and C. W. Hughes, Parameterization of ocean selfattraction and loading in numerical models of the ocean circulation, J. Geophys. Res._Oceans, 109, C03037, doi:10.1029/2003JC002034, 2004.

Takahashi, R., On seismic sea waves caused by deformations of the sea bottom, Bull. Earthq. Res. Inst., 20, 375-400, 1942 (in Japanese with English abstract).

Tamisiea, M. E., E. M. Hill, R. M. Ponte, J. L. Davis, I. Velicogna, and N. T. Vinogradova, Impact of self-attraction and loading on the annual cycle in sea level, J. Geophys. Res.-Oceans, 115, C07004, doi:10.1029/2009JC005687, 2010 .

Tang, L., V. V. Titov, and C. D. Chamberlin, Development, testing, and applications of site-specific tsunami inundation models for real-time forecasting, J. Geophys. Res.-Oceans, 114, C12025, doi:10.1029/2009JC005476, 2009.

Tang, L., V. V. Titov, E. N. Bernard, Y. Wei, C. D. Chamberlin, J. C. Newman, H. O. Mofjeld, D. Arcas, M. C. Eble, C. Moore, B. Uslu, C. Pells, M. Spillane, L. Wright, and E. Gica, Direct energy estimation of the 2011 Japan tsunami using deep-ocean pressure measurements, J. Geophys. Res.-Oceans, 117, C08008, doi:10.1029/2011JC007635, 2012.

Tsai, V. C., J.-P. Ampuero, H. Kanamori, and D. J. Stevenson, Estimating the effect of Earth elasticity and variable water density on tsunami speeds, Geophys. Res. Lett., 40, 492-496, doi:10.1002/grl.50147, 2013. Tsushima, H., K. Hirata, Y. Hayashi, Y. Tanioka, K. Kimura, S. Sakai, M. Shinohara, T. Kanazawa, R. Hino, and K. Maeda, Near-field tsunami forecasting using offshore tsunami data from the 2011 off the Pacific coast of Tohoku Earthquake, Earth Planets Space, 63, 821-826, doi:10.5047/eps.2011.06.052, 2011.

Unoki, S., Waves and tides in a density-stratified ocean, in Physical Oceanography in Coastal Seas, 329-397, Tokai University Press, Tokyo, 1993 (in Japanese).

Ward, S. N., Relationships of tsunami generation and an earthquake source, J. Phys. Earth, 28, 441-474, doi:10.4294/jpe1952.28.441, 1980.

Watada, S., S. Kusumoto, Y. Fujii, and K. Satake, Cause of delayed first peak and reversed initial phase of distant tsunami, Abstract NH43B1649, 2012 AGU Fall Meeting, 2012.

Wei, Y., E. N. Bernard, L. Tang, R. Weiss, V. V. Titov, C. Moore, M. Spillane, M. Hopkins, and U. Kânoğlu, Real-time experimental forecast 
of the Peruvian tsunami of August 2007 for U.S. coastlines, Geophys. Res. Lett., 35, L04609, doi:10.1029/2007GL032250, 2008.

Yoon, J.-H. and I. Yasuda, Dynamics of the Kuroshio large meander: Two-layer model, J. Phys. Oceanogr., 17, 66-81, doi:10.1175/1520-
0485(1987)017<0066:DOTKLM>2.0.CO;2, 1987.

D. Inazu (e-mail: inazud@bosai.go.jp) and T. Saito 